\title{
Defining and Measuring Coproduction: \\ Deriving Lessons from Practicing Local Government Managers
}

\author{
Accepted at Public Administration Review
}

Jeffrey (Jeff) L. Brudney (Ph.D.) was the Betty and Dan Cameron Family Distinguished Professor of Innovation in the Nonprofit Sector, Department of Public and International Affairs, University of North Carolina Wilmington, Wilmington, NC, USA. His research focused on nonprofit management, public service delivery, research methods and statistics, and volunteering and volunteer programs.

Email: brudneyj@uncw.edu

Yuan (Daniel) Cheng (Ph.D.) is an Assistant Professor in the Humphrey School of Public Affairs at the University of Minnesota. His research focuses on government-nonprofit relations, coproduction, and the distributional and performance implications of cross-sectoral collaboration.

Email: cheng838@umn.edu

Lucas Meijs (Ph.D.) is a Professor Rotterdam School of Management, Erasmus University Rotterdam, Netherlands. His current research focuses on issues related to strategic philanthropy, volunteer/non-profit management, corporate community involvement, voluntary energy as a natural resource and involved learning (life-long development by volunteering).

Email:1meys@rsm.nl 


\section{Acknowledgments:}

We thank Beth Gazley, Kathy Quick, Mark Levin, Nyle Zikmund, Chris Heineman, Heidi Nelson, and Kurt Ulrich for their comments and their help in the interpretations of our findings. We also thank the Editor and Peer Reviewers for Public Administration Review for their comments and suggestions. Finally, we want to thank Laura Goddeeris and Berna Oztekin from the ICMA survey research team for their assistance and support for this research project. The authors are solely responsible for the contents.

\section{Special Note:}

Jeffrey L. Brudney: Deceased.

Jeffrey L. Brudney: In loving memory of our beloved friend, coauthor, and mentor. This manuscript would not exist without you. Thank you for paving the way, for pushing the field forward, for setting an example of excellence and kindness, and for cultivating generations of scholars. We deeply miss you. 


\title{
Defining and Measuring Coproduction:
}

\section{Deriving Lessons from Practicing Local Government Managers}

\author{
Abstract \\ Following a lapse in scholarly attention, coproduction, the joint production of services by \\ government officials and citizens, has re-emerged as an important topic. However, the field lacks \\ information on broad parameters of coproduction implementation and how public managers view \\ coproduction. To address the lacuna, this study examines patterns of implementation of \\ coproduction in a national sample of municipalities and counties in the U.S. According to their \\ chief administrators, nearly half these governments have implemented one or more stages of \\ coproduction, although co-delivery of services occurs least often. Empirical analysis suggests \\ that the implementation of coproduction, as perceived by local government managers, can be \\ measured along a unidimensional scale and that this measurement scale is robust across different \\ subgroups. We also find that local governments that have larger population, provide more \\ services, have more professional forms of administration, and are located in the western U.S. \\ more often implement elements of coproduction.
}




\title{
Defining and Measuring Coproduction: \\ Deriving Lessons from Practicing Local Government Managers
}

\begin{abstract}
Evidence for Practice
1. Coproduction can be considered as a series of stages or phases: co-planning, co-designing, codelivering, and co-assessing.
\end{abstract}

2. From the perspective of public managers, local governments' involvement of citizens in planning, designing, delivering, and assessing services is interconnected. If local governments involve citizens in one type of coproduction, they are more likely to involve citizens in other types of coproduction of the same public service or somewhere else.

3. Although the implementation of any stage or phase of coproduction can prove demanding, from the perspectives of practicing local government managers, co-delivering services occurs least frequently and likely presents the greatest challenges.

4. Local governments with larger population, those providing more services, those with a more professionalized form of administration, and those located in the western region of the United States are more likely to engage in stages or phases of coproduction. 


\section{Defining and Measuring Coproduction: \\ Deriving Lessons from Practicing Local Government Managers}

As with any definition, the issue is not whether the interpretations of coproduction found in the literature are valid, but whether they are useful. That is, coproduction should be defined in a way that is relevant both to policymakers interested in implementing or evaluating coproduction programs and to academics concerned with operationalizing the concept in actual service delivery situations. (Brudney and England, 1983, p. 61, emphasis in the original)

Nearly forty years ago in 1981 Dr. Elinor Ostrom and her colleagues in the Workshop in Political Theory and Policy Analysis at Indiana University introduced the concept of "coproduction," or the joint production of services by government officials and lay citizens, to students of political science and public administration (Parks et al. 1981). It did not take long before scholars became concerned with appropriate conceptualization. Indeed, even the pioneering work of the Indiana Workshop members professed the intention to "explore the concept of coproduction in an effort to sharpen the definition of that concept and add rigor to our understanding" (Parks et al. 1981, p. 1001). Writing shortly thereafter, Brudney and England (1983) -- from whose Public Administration Review article the above quotation emanates -sought to elucidate the coproduction concept in a way useful for academic researchers and practicing public managers alike.

In the ensuing years, academic researchers have critiqued and proposed definitions of coproduction. The definitions have become ever more refined, with scholars identifying and 
emphasizing the differences among various stages or phases of coproduction, such as coplanning, co-designing, co-delivering, and co-assessing services. While scholars have proposed and debated appropriate conceptualization, comparatively little attention has been devoted to how coproduction, including its different stages or phases, has been understood and perceived by local government managers. The field lacks information on the broad parameters of coproduction implementation, such as the measurement of the coproduction construct as well as the extent and patterns of its adoption.

The present inquiry addresses this lacuna. To our knowledge, the study offers the first systematic examination of coproduction implementation based on large, representative samples of practicing public managers, here, local government managers of municipalities and counties across the United States. We also develop and validate the scale of coproduction using the latent trait model to aid comparisons of the perceived level of coproduction implementation by government managers across communities, thus responding to the call for measurement equivalence in comparative public administration (Cheng 2020; Jilke, Meulemen and Van de Walle 2015).

The findings show that nearly half of these responding government managers assessed that their local governments have implemented one or more of the main phases or stages of coproduction of services identified in the literature: co-planning, co-designing, co-delivering, and co-assessing. Closer examination of these results through dimensional analyses indicates that their perceived adoption of the different phases or stages of coproduction is highly intercorrelated and fits a unidimensional solution. We explore the extent to which this unidimensional solution is robust to different factors that we had anticipated would affect government managers' perceived levels of implementation of coproduction, such as the form of 
government, government professionalism, service demands, population, and region. The findings suggest that coproduction can be measured as citizens' engagement in various stages and phases of public service provision, according to the responses of the government practitioners. Implementation of coproduction in a jurisdiction seems to extend across the service cycle with high inter-correlations among its constituent elements.

Based on the research literature, in the next section of the article, we develop alternative expectations concerning the extent and character of coproduction implementation, which guide our empirical analysis. The article then turns to the conceptualization and measurement of coproduction in the present study, including operationalization of the phases or stages of coproduction: The data consist of the responses of a national sample of Local government managers of municipalities and counties across the United States to a systematic survey conducted by the International City/County Management Association (ICMA) in 2017. We next present the results of our analysis. We conclude with a discussion of the findings and their implications.

\section{Patterns of Coproduction Implementation:}

\section{Alternative Expectations for Empirical Analysis}

Studies of coproduction often bemoan the lack of definitional clarity in research in the field (Voorberg, Bekkers and Tummers 2015) and strive to address it. The authors of a recent essay, Dudau, Glennon, and Verschuere (2019, p. 1581) find, "It would seem that there are as many definitions as there are articles and books about co-production." Public Administration Review alone has published no less than five articles concerned with conceptualization, most recently by Nabatchi, Sancino, and Sicilia (2017), but also Brandsen and Honingh (2016), 
Bovaird (2007), Brudney and England (1983), and Whitaker (1980). Nor are these studies the sole efforts committed to parsing and distinguishing coproduction more precisely. A systematic review of the coproduction literature conducted by Voorberg, Bekkers, and Tummers (2015) uncovered 122 articles and books on coproduction and cocreation. The authors found that nearly one in five studies $(18 \%)$ aimed at the identification or conceptualization of different types of coproduction and were not concerned with discussing further outcomes.

Nabatchi, Sancino, and Sicilia (2017, p. 766) observe that "Coproduction is often the subject of exploratory, single case study research, seldom the subject of explanatory research, and rarely if ever, the subject of comparative research and meta-analysis." In their systematic review Voorberg, Bekkers, and Tummers (2015) found that studies of cocreation/coproduction were predominantly single case studies (51\%) or comparative case studies (34\%) and typically used qualitative methods, such as interviews and document analysis. Thus, the bulk of the coproduction studies draw substantial attention to the context of coproduction and its distinctiveness, perhaps unwittingly contributing to the plethora of definitions and nuance in the literature. Just 15 percent of the coproduction studies employed quantitative methods (Voorberg, Bekkers, and Tummers, 2015). Another systematic literature review of more than 1,100 academic articles published since the term first emerged in the late 1970s (nearly two-thirds of them published since 2015) by Sicilia, Sancino, Nabatchi, and Guarini (2019, p. 238) "revealed that empirical research on co-production in public services is lagging behind conceptual, theoretical, and descriptive research."

Given the attention accorded to the distinctiveness of coproduction and the contextual descriptions and explanations found in the literature, one might well conclude that adoption of coproduction, its stages or phases, would be highly unique across locales, reflecting differences 
in processes, conditions, and government acceptance and support. In the coproduction literature, some scholars such as Brandsen and Pestoff (2006) treat coproduction as a distinctive mode of cooperation between citizens, the third sector, and government. From this perspective, coproduction is restricted to individual citizens participating in the implementation of public services, while co-governance has an emphasis on service planning and policy formulation, and co-management on inter-organizational interactions. Using evidence from the public service activities of park-supporting nonprofits in large U.S. cities, Cheng (2019) finds empirical support for the argument of Brandsen and Pestoff (2006) about different modes of cooperation between these nonprofits and government. Park-supporting activities by these nonprofits seem to load on distinctive dimensions, especially for service planning and design. Gazley, Cheng, and LaFontant (2018) further demonstrate that the patterns of these modes of cooperation seem to differ at the state and federal levels for these park-supporting charities: National park charities have developed a differential pattern of support, while state park-supporting charities demonstrate a more generalized form of support.

This perspective concerning the unique characteristics of different forms or stages of coproduction also flows from the numerous, disparate examples provided by Bovaird (2007). For example, following a conceptual framework of coproduction based on the range of professionaluser relationships, Bovaird (2007, p. 848) argues that "different types (of coproduction) will evolve along path-dependent lines from different antecedents and will be shaped by different motivations on behalf of both professionalized service providers and the users and communities involved." These analyses suggest that the forms or stages of coproduction are quite distinct and call for different skills, preparation, and acceptance across local governments to support and implement them. From this perspective, we would expect to see implementation diverge 
dramatically, with cities and counties adopting one or another stage(s) of coproduction in a mainly idiosyncratic manner. If so, correlation analysis should reveal low, if any, statistically significant inter-relationships across the stages of coproduction in samples of local governments.

An opposing hypothesis is also possibly grounded in an alternative interpretation of the coproduction literature. Based on their systematic literature review, Voorberg, Bekkers, and Tummers (2015, p. 1340) report, "When we compared the record definitions of co-creation/coproduction, we see that -- to a large extent -- both are defined similarly.... Hence, we can conclude that empirically co-creation and co-production are used as interchangeable concepts. However, the question can be raised whether this supports the creation of conceptual clarity." In other words, while different definitions of coproduction may capture various dimensions of coproduction, they all point to the overall underlying coproduction construct. It is important to tease out these dimensions and create better conceptual clarity of coproduction. Although researchers continue to propose and contest definitions, the movement toward overlap in the way that scholars conceive apparently distinctive aspects of coproduction, as expressed by Voorberg, Bekkers, and Tummers (2015), may signal greater coalescence in the field, rather than less. A primary reason for the overlap is that despite the differences identified in leading academic treatments of coproduction, scholars see the concept similarly (see, for example, Nabatchi, Sancino, and Sicilia, 2017, “Table 1. A Sampling of Coproduction Definitions,” p. 768), as highlighting the valuable role that citizens can and do play as partners in some/all stages/phases of the service cycle, contributing through their service-directed activities to consumer-production with paid service agents, as formulated in the classic study by Parks, et al. (1981). Dudau, Glennon, and Verschuere (2019, pp. 1581-1582) summarize, "what different definitions have in common is that (a) they constitute a part of the production process of services, (b) they refer to 
collaboration between professional service providers and citizens/users, and that (c) active input by citizens is needed to shape the service."

Based on a review of the numerous definitions of coproduction, spanning earlier efforts such as Parks et al. (1981), Whitaker (1980), and Brudney and England (1983), and extending through more contemporary treatments, such as Bovaird (2007), Brandsen and Honingh (2016), and Loeffler and Bovaird (2016), Nabatchi, Sancino, and Sicilia (2017) delineate the conceptual underpinnings for this point of view in a new typology. Their typology integrates the various meanings along two dimensions or "sides" of coproduction. The "co" side emanates from research by Brudney and England (1983), who distinguished individual, group, and collective levels of public participation in coproduction. The "production" side has roots in Bovaird (2007), who identified different temporal phases of the service cycle in which citizens might be involved, in the co-commissioning, co-designing, co-delivery, and co-assessment of services. Nabatchi, Sancino, and Sicilia (2017, p. 771) observe that with respect to their temporal nature, co-commissioning is prospective, co-designing is prospective or concurrent, co-delivery is concurrent, and co-assessment is retrospective (although sometimes with prospective elements). Combining the "who" and the "when" dimensions yields a new typology of coproduction that incorporates three levels of citizen participation across four phases of the service cycle. This conceptualization draws attention to progression and possible inter-relationships across coproductive activities in the service cycle. Nabatchi, Sancino, and Sicilia (2017, p. 769) define "coproduction as an umbrella concept that captures a wide variety of activities that can occur in any phase of the public service cycle and in which state actors and lay actors work together to produce benefits." 
Following this formulation, we might conceive of coproduction as an underlying construct whose existence and extent can be measured by the participation of citizens across the stages or phases of the service cycle. Although the implementation of all phases or stages need not occur simultaneously, or in a prescribed order, or observe a temporal sequence as suggested by Nabatchi, Sancino, and Sicilia (2017) -- modern public management holds that the policymaking and implementation cycle is iterative, which suggests that there is no clear temporal relationship between stages (Nowlin 2011; Sabatier 2007) -- implementation of coproduction can be conceived along a continuum incorporating and spanning the different phases or stages. In this view, we would expect to find statistical inter-relationships across the implementation of the various phases or stages of coproduction. By contrast, in the first perspective highlighting the distinctiveness of different aspects of coproduction we would expect to find scant, if any, statistically significant inter-relationships in coproduction implementation across the phases or stages of the service cycle. In this research, we use the reports provided by samples of local government managers -- whose voices have been largely "silent" in the coproduction literature -- to evaluate which of these expectations seems to have greater support in practice.

Indeed, as voluminous as the coproduction literature may be, it has not generated findings from large samples of local government managers concerning implementation, despite the need for them (Sicilia, Sancino, Nabatchi, and Guarini 2019). The literature does include large sample surveys based on citizen respondents predominantly in a European context (for example, Bovaird et al. 2021; Bovaird, Van Ryzin, Löffler, and Parrado 2015; Loeffler, Parrado, Bovaird, and Van Ryzin 2008; Parrado, Van Ryzin, Bovaird, and Löffler 2013), as well as evidence from large survey and field experiments of citizen participants, for example, regarding the willingness and 
capacity to coproduce (Jakobsen 2013; Letki and Steen 2021; Riccucci, Van Ryzin, and Li 2015), and trust in government (Kang and Van Ryzin 2019). There are also large sample organizational studies focusing on the conditions under which nonprofit organizations emerge to coproduce public services with government agencies (Cheng 2019; Gazley, LaFontant and Cheng 2020; Paarlberg and Gen 2009).

While citizens and nonprofit organizations are certainly critical in understanding coproduction as service users and producers, what is yet to appear in the literature, is the other side of coproduction - how local government managers perceive the level of coproduction adoption in their jurisdictions. Although public managers are hardly the only actors involved in the implementation of coproduction, they are the essential and critical actors in the coproduction paradigm who could provide systematic information on the scope and extent of implementation of coproduction across governments, compared to other important actors who may be involved, including nonprofit organizations, professional associations, citizen and community groups, lay citizens and clients, etc. (for example, Brandsen and Pestoff, 2006; Brandsen, Steen, and Verschuere 2018; Bovaird 2007; Benjamin and Brudney 2019; Pestoff 2019). Public managers also play critical roles in ensuring the equity and performance of coproduction and public service delivery (Gazley, LaFontant and Cheng 2020; Jakobsen and Andersen 2013).

As a result, the field lacks even the most rudimentary knowledge concerning the extent of implementation of coproduction across well-defined samples of governments, or the interrelationships among the different stages or phases. The extant literature stems primarily from qualitative research using case studies and small samples -- characteristics which inadvertently tend to accentuate differences in conceptualization and implementation in particular locales rather than a generalization of findings across them, and consequent calls from academicians to 
distinguish and clarify further the coproduction concept. As Voorberg, Bekkers, and Tummers (2015, p. 1333) exhort, "more quantitative studies are welcome, given the qualitative, case study, dominance in the field," a call echoed by Nabatchi, Sancino, and Sicilia (2017) and other scholars (for example, Dudau, Glennon, and Verschuere 2019).

Accordingly, in this research, we survey representative samples of local government managers concerning their experiences with coproduction in municipalities and counties across the United States. Consistent with the coproduction literature, we conceive of coproduction as citizen involvement in the stages/phases of the service cycle identified by Nabatchi, Sancino, and Sicilia (2017): We query these public managers regarding whether their local government involves citizens in planning, designing, delivering, and assessing public services. We test the measurement model proposed in Figure lin the full sample and evaluate its robustness (invariance) across important subsamples differentiated by the type of government, government professionalism, service demands, population, and region. From this analysis, we produce a mapping of the broad contours of coproduction implementation according to practicing local government managers, which has been absent from the coproduction literature heretofore.

\section{Data and Methodology}

To examine the patterns and implementation of coproduction perceived by local government managers, we worked with the International City/County Management Association (ICMA) to add a series of questions related to how local governments involves citizens in different aspects of public service provision in its 2017 Alternative Service Delivery (ASD) Survey of municipalities and counties in the United States. ICMA has assessed local government practices, experiences, and policies in alternative service delivery for more than 
three decades. It is widely regarded as one of the most authoritative and expansive surveys of U.S. local governments. Public Administration Review alone has published multiple studies relying on ICMA surveys as their main data sources to understand local government behaviors, for example how U.S. local governments provide public services (Marvel and Marvel 2007) and respond to fiscal stress (Warner, Aldag and Kim 2020), cyberattacks (Norris, Mateczun and Joshi 2019), and natural disasters (Dzigbede, Willoughby and Gehl 2020).

With the support of the ICMA survey research and development team, we drafted the questions related to different types of coproduction as suggested by the existing literature (Bovaird 2007; Nabatchi et al 2017). An expert volunteer advisory group at ICMA was consulted before the questions were finalized in the survey instrument to make sure those questions can be sufficiently comprehended by local government managers. Because of the extensive coverage of the ICMA ASD surveys, local government managers are expected and encouraged to consult and engage their staff when filling out the survey ${ }^{1}$. Although we may not expect local government managers to know every aspect of local government management in detail compared to department heads and service providers, their unique position in the city management hierarchy between the city council and various functional departments offer them the best position as a single contact to assess jurisdictional level efforts in engage citizens in different stages of public service provision. Their experiences across different administrative levels and functional departments in local governments also equip them with a comprehensive and sophisticated understanding of public services provided by their local governments. According to a survey of local government managers' career paths in large U.S. cities, local government managers on average have worked in localities where they serve for approximately 12 years, and they often move from lower-level administrative positions gradually to current leadership positions 
(Watson and Hasset 2004). Local government managers are increasingly expected by the public and elected officials to facilitate community participation, representation, and partnership (Nalbandian 1999; Thomas 2013).

The ICMA ASD survey including the questions of coproduction was administered in June 2017. Paper surveys were mailed to 13,777 local government managers of all municipalities with a population of over 2,500 and all counties across the United States. Responses were received from 2,343 local governments, yielding a response rate of 17 percent with a 2 percent margin of error (International City/County Management Association, 2019). Although some research has critiqued the IMCA Alternative Service Delivery surveys (Lamothe, Lamothe, and Bell, 2018), they have provided vital source data for numerous peer-reviewed publications; in addition, the coproduction items used in the present study were created for the 2017 ICMA ASD and are not subject to the critique, which was based on retrospective analysis of surveys from more than a decade earlier.

The key variable in our analysis is local government managers' perceived level of citizen participation in coproduction across U.S. municipalities and counties. Rather than query public managers regarding involvement in "coproduction," a term likely unknown to them and without a standard meaning for practitioners, the survey asked respondents about citizen activity in four stages or phases of coproduction, without referencing this term.

The ICMA survey presented a battery of four questions to respondents regarding ways in which citizens might be involved with their local government in the service cycle. To introduce the questions the survey asked, "Does your local government involve individual citizens, groups of citizens, and/or citizens as a whole (i.e., the entire community) in any of the following ways?" Because local governments might well involve citizens, groups of citizens, and the entire 
community in coproduction activity, the introduction specified, "check all applicable," and all of the coproduction items allowed for multiple responses. The ICMA queried participating public managers regarding citizen involvement in their municipality or county in four stages or phases of coproduction:

"In planning services (i.e. decisions on service policies and funding)"

"In designing services (i.e. decisions on how services will be arranged or organized)"

"In delivering services (i.e. using citizens' labor/ expertise to help deliver services)"

“In assessing services (i.e. seeking citizens' online ratings or other reviews of services)" As discussed above, the field lacks basic information on the extent of coproduction implementation across local jurisdictions, as perceived by local government managers. The large sample of local governments responding to the ICMA ASD Survey $(\mathrm{N}=2,343)$, which may help to compensate for the low response rate, allows us to explore implementation across the sample. In the analysis to follow we examine the four indicators of coproduction activities and the interrelationships among them. Following Jilke, Meuleman, and Van de Walle (2015)'s recommendation to check the measurement equivalence in different settings or subsamples, we also evaluate whether these interrelationships are robust across important subgroupings: whether the jurisdiction is a municipality or a county, its form of government, size (population) of the jurisdiction, level of service demands (number of services provided), and its location or region in the United States. We seek to assess whether local government managers in different types of jurisdictions (based on the criteria listed above) perceive coproduction implementation similarly or differently. Exploration of these contextual factors can also help to provide a preliminary understanding of the patterns of coproduction implementation across U.S. local governments. 
We further discuss the implications of our findings for a more comprehensive analysis of coproduction implementation by future studies.

\section{Findings}

The first part of the analysis provides basic information on the extent of local government managers' perceived level of implementation of coproduction across local governments in the U.S. We then turn to the question of possible inter-relationships among the four stages or phases of coproduction. In this part of the analysis we present the correlations among the four coproduction indicators and perform factor analysis to probe these inter-relationships more systematically; because these items are measured at a binary (yes/no) level, we use tetrachoric correlations as input to the factor analysis. To test the consistency or invariance of the dimensional solution we replicate and compare the factor analyses of coproduction implementation for important subgroupings of local governments: municipalities versus counties, more versus less professionalized local governments, smaller versus larger jurisdictions, those with lower versus higher service demands, and those located in different regions of the United States. To create a valid measure of coproduction, we then use the latent trait model to develop a scale of the coproduction construct. Based on these findings we are able to describe the broad contours of coproduction implementation across U.S. local governments as perceived by their public managers.

Table 1 presents the frequencies of implementation of coproductive activities by municipalities and counties across the United States, according to the responses of their local government managers to the ICMA 2017 Alternative Service Delivery Survey. Overall, about half of the public managers represented in the sample responded that their local governments 
have implemented one or more of the stages or phases of coproduction. For specific types of coproduction, perhaps because working with citizens to plan services has a lengthy history in U.S. local government, the highest percentage of citizen involvement (46.6\%) in coproductive activities occurs in this domain. By contrast, the area with the lowest percentage of involvement is the most novel, the co-delivery -- or "coproduction" -- of services; about one-quarter of the responding public managers $(27.33 \%)$ report their local governments involve citizens in the delivery of services. In between these levels with respect to the frequency of implementation across U.S. local governments lie co-designing services, with 30.47 percent of the local governments involved in this activity, and co-assessing, with 35.06 percent involved. Pairwise ttests show that the frequencies of local governments involving citizens in co-planning, co-design, co-delivery, and co-assessment are statistically different from each other, suggesting the validity of differentiating various types of coproduction based on the stages of the public service provision cycle. Overall, our results suggest that implementation of a stage(s) of coproduction appears to be common across U.S. local governments, although co-delivery lags the other stages or phases, as perceived by local government managers.

[Table 1 about here]

The findings displayed in Table 1 suggest the frequency of implementation of the stages or phases of coproduction in a sizeable sample of local governments. The findings do not reveal the pattern of implementation, however. The inter-correlations presented in Table 2 allow us to evaluate empirically the contrasting expectations that we had developed above concerning the implementation of coproduction, viz., a pattern of few, if any, statistically significant interrelationships across the phases or stages of the service cycle, versus high inter-correlations across 
them. Since the input data for the correlations are binary responses of the local government managers regarding any citizen involvement in a stage or phase of coproduction, we use tetrachoric correlations to perform this part of the analysis and subsequently for factor analysis. With the assumption of a bivariate normal distribution of the latent continuous variables, tetrachoric correlations establish a threshold model for the binary variables (Muthén, 1978). Table 2 displays the matrix of tetrachoric correlations among the coproduction items.

[Table 2 about here]

Examination of the matrix in Table 2 leaves no doubt that implementation of coproduction by U.S. local governments, as perceived by local government managers, reveals a pattern of high intercorrelation across the stages or phases of the service cycle; the correlations range from $.75(.7498$, between co-planning and co-assessing) to nearly $.90(.8833$, between coplanning and co-designing). Rather than a disparate, sporadic record of implementation, in which a municipality or county might implement one or another of the coproduction stages or phases, the very high tetrachoric correlations shown in Table 2 suggest that implementation in a jurisdiction tends to flow across the stages or phases of the service cycle, although a clear temporal ordering cannot be discerned with the cross-sectional data. If so, we would expect the implementation data to fit a one-dimensional solution in a technique such as factor analysis, designed to evaluate dimensionality. Table 3 summarizes the results of the factor analysis of the items tapping the four coproduction stages or phases.

[Table 3 about here]

As the matrix of tetrachoric correlations in Table 2 intimated, factor analysis shows that implementation of the stages or phases of coproduction is decidedly unidimensional. Three of the four stages or phases of coproduction have loadings surpassing .90 , and the smallest loading 
is nearly as great (.8453 for co-assessing), on the single factor or dimension derived from the analysis, which we would label "coproduction." Implementation of coproduction by municipalities and counties seems unidimensional across the constituent stages or phases. Table 4 turns to the question of whether this conception of coproduction implementation as unidimensional is robust or invariant to important contextual features of local governments, such as jurisdiction, the form of government, population, service demands, and region.

[Table 4 about here]

The factor analysis results shown in Table 4 demonstrate that the structure of public managers' perceived level of coproduction implementation by their local governments is remarkably consistent (invariant) across the contextual characteristics. Regardless of whether we consider municipalities versus counties, local governments serving larger versus smaller populations (categorized as above or below the median population for the sample), those offering more or fewer services (categorized as those providing more or fewer services than the median for the sample), or those with more or less professionalized forms of government (categorized as local governments that have a managerial form, Council-Manager for municipalities and Council-County Administrator for counties, versus all other forms), or region, factor analysis consistently generates a unidimensional solution. All of the factor loadings of the coproduction items on the single dimension surpass .80 (and are usually much larger), and statistical tests to evaluate the possibility and efficiency of additional factors fall far below threshold values. Rather than demonstrating a sporadic pattern of implementation by local governments, in practice implementation of coproduction seems to develop iteratively along a continuum toward enactment throughout the service cycle. 
Following the exploratory factor analysis, we use the latent trait model, which is a confirmatory factor analysis method to accommodate binary indicators, to provide a more formal test of the measurement model we propose in Figure 1. The latent trait model takes information from all binary indicators into consideration when generating the scale of the latent construct, while other scaling methodologies (for example, the summative scale) may suffer from the risk of homogenization (Muthén, 1983). We use the gsem function of Stata/SE 16.0 to estimate the latent trait model. As shown in Figure 1, all four indicators load on the principal coproduction construct at the $\mathrm{p}<.01$ level, thus suggesting that the latent trait model validates our proposed one-dimensional measurement model. We further develop the coproduction scale using the latent trait model to measure the level of coproduction and to guide the following analysis.

[Figure 1 about here]

The final aspect of the empirical analysis aims to describe the broad contours of coproduction implementation across U.S. local governments as perceived by their public managers, a topic yet to be systematically addressed in the research literature. For this analysis, we can compare implementation across the important contextual features or subgroupings depicted in Table 4.

[Table 5 about here]

According to the results shown in Table 5, local government managers' perceived level of coproduction implementation demonstrates marked differences by the contextual features or subgroupings. In the United States, municipalities (56.37\%) are more likely than counties $(49.57 \%)$ to implement any stage of coproduction; local governments with larger $(58.48 \%)$ rather than smaller $(51.77 \%)$ populations are also more likely, as are those providing more services $(64.57 \%)$ rather than fewer $(44.62 \%)$; those with more professionalized administration $(61.35 \%)$ 
rather than less $(56.27 \%)$ are similarly more likely to implement coproduction (any stage). Finally, local governments in western states $(70.36 \%)$ are most likely to implement, and those located in the north-central U.S. (48.57\%) are the least. All differences in percentages attain statistical significance, minimally at the $\mathrm{p}<.05$ level.

\section{Discussion}

The findings of this study show that, from the perspective of practicing local government managers, nearly half of municipal and county governments in the United States have implemented one or more of the main stages or phases of coproduction: co-planning, codesigning, co-delivering, or co-assessing services, as perceived by their practicing government managers. Co-delivering services, the impetus of the coproduction literature and its most novel aspect, lags in implementation at about one-quarter of the national sample.

Regarding the structure of coproduction implementation, on the one hand, the literature might well lead one to believe that adoption of the various stages or phases of coproduction is highly contextual, depending on the specific conditions and circumstances of the local government as well as the community it serves (Cheng 2019; Gazley et al. 2018). Implementation of coproduction might, thus, have a multidimensional interpretation. On the other hand, some literature might intimate a unidimensional interpretation in which implementation progresses iteratively and dynamically over the stages or phases of coproduction of services, co-planning, co-designing, co-delivering, and co-assessing (Nabatchi et al. 2017). Support for either pattern (or a combination) is an empirical matter, which the observations of local government managers can help us to address. However, on-the-ground information 
regarding the implementation of coproduction gleaned from large samples of practicing public managers has yet to inform the coproduction literature.

The present inquiry begins to address this lacuna. We rely on data collected by the International City/County Management Association in its 2017 Alternative Service Delivery Survey of local government managers in municipalities and counties to document coproduction implementation across local governments in the United States. These data strongly support the interpretation of coproduction implementation as proceeding iteratively along a single continuum or dimension, rather than the adoption of particular phases or parts as distinctive, isolated, or prerequisite activities of local governments. This pattern garners empirical support in the high inter-correlations among the items tapping the stages or phases of coproduction implementation, and the dimensional analyses of these items for the sample as a whole as well as for important subgroupings of the local governments. While the structure of coproduction implementation may be invariant for cities and counties, the findings show that local governments differ significantly in implementation. Municipalities, jurisdictions with larger populations, those providing more services, and those with more professionalized administration are more likely to implement any coproduction stage or phase $(\mathrm{p}<.05)$.

From the questions presented in the ICMA Alternative Service Delivery Survey, at least in the United States, only about one-quarter of public managers report that their local governments involve citizens in the co-delivery of public services. This comparatively low level of reported co-delivering indicates that as opposed to some scholarly literature, which regards co-delivery as the most classic and frequent form of coproduction (Alford 2016; Bovaird et al. 2021; Osborne 2018; Palumbo, Fakhar and Manesh 2021; Parks et al. 1981), top public managers in the hierarchy of local governments do not see co-delivering as inherent to public 
service provision. While this result is counterintuitive given our status of knowledge about coproduction, often drawn from the experiences of individual citizens and street-level bureaucrats who engage in service delivery on a daily basis (e.g., Bovaird et al. 2021; Letki and Steen 2021), it is not surprising from the positionality of these practicing local government managers. From their top-down perspective in the hierarchy of local governments, the design and delivery of services are often the responsibility of professional service providers and are tied to specific services. The concurrent nature of co-delivery also makes it harder to regularly rely on citizens to coproduce public services. Local government managers are likely to be called upon to engage in co-delivery only when problems arise during service delivery².

Compared to service delivery and design, co-planning and co-assessment are often mandated by the city council or considered a norm of procedural democracy for public service provision. Local government managers can also design prospective or retrospective processes to engage citizens in those stages of coproduction (Nabatchi et al. 2017). Therefore, top public managers are more likely to report that their local governments systematically engage citizens in co-planning and co-design. These stakeholder-specific findings point to the importance of comparing and assessing the responses from citizens, street-level bureaucrats, local government managers, and elected officials on the state of coproduction implementation by local governments. Based on the above discussions, we propose that in the spectrum of various stages of coproduction, citizens and street-level bureaucrats are more likely to offer a more accurate assessment and report a higher frequency of the implementation of co-delivering and co-design for specific services, while local government managers and elected officials co-planning and coassessment for public services at the jurisdictional level. 
Although we might expect that smaller governments would be more likely to implement elements of coproduction, perhaps as a cost-saving measure as suggested by some earlier coproduction research (for example, Brudney and England 1983), the results of the present inquiry do not support this assumption. By contrast, the findings intimate that local governments in larger jurisdictions facing greater service demands and having the professional capacity to deal with them may be more likely to turn to coproduction of services. This result coincides with Paarlberg and Gen's (2009) finding that the ability for citizens to participate in coproduction depends on the supply of human and financial resources in the community. However, this finding does part ways with Alonso, Andrews, Clifton, and Diaz-Fuentes's (2019) finding that the quantity and quality of public services are negatively correlated to citizens' willingness to coproduce. One possible explanation is that although larger jurisdictions and localities with more services provided by their local governments tend to generate less demand for citizen coproduction, they also create more opportunities for their citizens to engage in coproduction. Demand and supply factors work simultaneously to influence the implementation of coproduction (Paarlberg and Gen 2009).

In addition, regional differences in coproduction attain statistical significance $(\mathrm{p}<.05)$, which may suggest that factors at the regional level may systematically shape the implementation of coproduction. For example, future studies could examine whether the political culture of different areas affects the likelihood of implementation (Pestoff, 2019; McMullin 2019; Uzochukwu and Thomas 2018). Administrative culture and social capital also tend to have a strong impact on coproduction, as these characteristics present strong regional variations (Alonso et al. 2019; Thijssen and Van Dooren 2016). 


\section{Limitations}

We hope that our study has yielded knowledge in an emerging area of coproduction inquiry, to assess its measurement and describe the broad contours of implementation from the perspective of practicing local government managers. As with any study, however, ours is subject to limitations. First, our cross-sectional data emanate from one country at one point in time. Although these data cannot address temporal issues in coproduction implementation, our check on the robustness of the dimensional analysis allowed us to provide and examine findings across important subgroupings (jurisdiction, population, service demands, form of government, and geographic region), which suggested that implementation may vary according to these characteristics. A cross-national examination of these and other findings, across time, awaits further inquiry and may expose further limitations to our knowledge of coproduction (Dudau, Glennon, and Verschuere, 2019). As we have gained knowledge about coproduction in a specific national context, similar studies could be set up by taking a cross-national comparative approach thereby taking into consideration different state-citizen traditions

Second, as with previous Alternative Service Delivery Surveys conducted by the International City/County Management Association, the 2017 ASD Survey cannot boast high response rates; even so, ICMA reports that the margin of error (2 percent) is small (International City/County Management Association, 2019). Lamothe, Lamothe, and Bell (2018) have raised other questions concerning the ICMA data. However, their critique is based on much earlier ICMA Alternative Service Delivery surveys, administered in 2002 and 2007, in which the researchers attempted to verify responses more than ten years later with a very small sample, 70 officials of some 1,200-1,600 total responses. In addition, the items tapping coproduction of services examined in the present study did not appear in the earlier ICMA surveys but were 
created for the 2017 ICMA ASD survey; they are not the part of the survey that provoked the response of Lamothe, Lamothe, and Bell (2018).

Nevertheless, we recognize that due to the formatting and structure of the Alternative Service Delivery Survey, the four items concerning coproduction presented in the questionnaire are relatively brief. Although the items probe citizen involvement in the stages or phases of coproduction, co-planning, co-designing, co-delivering, and co-assessing, they cannot offer a complete description of such a dynamic concept, particularly with a binary response of whether local governments involve citizens in these activities or not. From these items, we cannot determine the specific services in which citizens may be involved, the activities included in each stage of coproduction, or the depth of citizen (or government) involvement in them. We are aware, furthermore, that these items do not allow us to distinguish the nature of citizen participation, which Arnstein (1969) and others have eloquently demonstrated is a highly subtle concept in itself. The local government manager respondents that ICMA has queried in its long history of surveys of U.S. local governments likely lack intimate knowledge of every service in their jurisdiction, and social desirability bias may arise in survey research concerning citizen involvement (Nederhof, 1985). Nevertheless, the position and communication channels of these officials within local government should afford them the information to answer these basic questions about their jurisdictions in the 2017 Alternative Delivery Survey knowledgeably, and as stated earlier, the ICMA questionnaire did not use unknown or non-standard language of "coproduction" but parsed the concept into citizen involvement in four stages or phases based on the literature. Given the "relatively shallow set of empirical studies" (Dudau, Glennon, and Verschuere, 2019, p. 1590) widely documented in the coproduction literature and our intention to provide an empirical description of the state of coproduction adoption from government officials, 
our survey research design and analysis generate a picture of implementation across a large sample of local governments that can guide further depth inquiry as well as cross-sectional analysis. Ultimately, given the current state of our knowledge in coproduction, we hope our study provides a starting point of systematically understanding coproduction implementation by local governments at the national level.

\section{Implications for Future Research}

The first implication of the present study flows from this last limitation. The large volume of qualitative single-case and comparative-case studies in the coproduction literature documented by Voorberg, Bekkers, and Tummers (2015) offers a rich canvas for painting the picture of coproduction implementation. By illustrating the ways and means in which citizens are involved in each of the stages or phases of coproduction for single services, these studies can help to fill the voids in detail and nuance that cannot be addressed through empirical analysis of the 2017 ASD cross-sectional survey. While we have endeavored to offer a description of the broad contours of coproduction implementation across municipalities and counties in the United States, the explanation of implementation by local governments lies beyond the scope of our study. Based on the extant literature, such an analysis would need to consider a considerable range of explanatory factors, including government fiscal capacity and limitations, citizen preferences, and the existence of other institutions to support service delivery. Ferris (1988) has provided a model that offers a useful point of departure. Alonso et al. (2019) and Thijssen and Van Dooren (2016) also develop promising empirical strategies and frameworks to take both individual level and community level characteristics into account when considering the implementation of coproduction. 
Second, the coproduction literature has been greatly concerned with appropriate conceptualization and measurement. Our findings confirm the existing typology of coproduction: while there are substantive differences among various types of coproduction based on the phrases of the service cycle, they all point to an umbrella term of coproduction (Nabatchi et al 2017). Our analysis suggests that research might profitably turn to integrate more systematically the views and experiences of large samples of practicing local government managers with coproduction, and compare them with the responses of citizens and street-level bureaucrats. From the perspective of local government managers, implementation of the different stages or phases of coproduction that the literature carefully distinguishes seems to develop iteratively from one stage to another, with no clear temporal relationship between its stages. Assisting public administration practitioners and scholars in addressing this transition and understanding the dynamic evolvement of different stages of coproduction might be a worthwhile goal for continuing research in this area.

\section{Conclusion}

Following Pollitt and Hupe (2011), Dudau, Glennon, and Verschuere (2019) express the concern that academicians may treat coproduction as a "magical concept" because it possesses breadth, normative attractiveness, consensus implications, and global marketability One way to begin to demystify the concept (although surely not the only way; see Dudau, Glennon, and Verschuere, 2019) is to parse it into discrete stages or phases -- as the literature has ably done (Nabatchi, Sancino, and Sicilia 2017 ) -- and to measure or operationalize it, as we have endeavored to do in the present study. Based on a large, systematic sample of practicing local government managers, our efforts offer a first attempt, which requires further development and 
refinement. Among other factors, improvement in measurement should take into account the number of services, types of services, and degree of citizen participation and activities in the different stages or phases of coproduction. Such improvement should be informed by the existing largely qualitative research on coproduction.

Based primarily on case studies and other qualitative methodologies, the substantial literature on coproduction has generated valuable information on the meaning of coproduction and its operation in specific contexts. To complement this knowledge, the present inquiry offers a systematic examination of the patterns of coproduction implementation across a large, national sample of municipalities and counties in the United States. According to local government managers of these jurisdictions, about half of their governments have implemented one or more of the main stages or phases of coproduction, co-planning, co-designing, co-delivering, and coassessing; co-delivery of services occurs least often. The results of the empirical analysis suggest that implementation of coproduction can be conceived along a unidimensional scale. The resulting scale can inform not only multi-methodological examination into coproduction incorporating quantitative as well as the qualitative approaches common in the literature but also more comprehensive multivariate models of implementation that can also extend the field. 


\section{Notes:}

1. This information is confirmed by the survey research and development team at ICMA. Their names are listed in the acknowledgement section.

2. To better understand and interpret our results, we interviewed four practicing local government managers, one retired local government manager, and two scholars who have deep expertise in citizen participation in local governments. Their names are listed in the acknowledge section. 


\section{References}

Alford, J. 2016. Co-Production, Interdependence and Publicness: Extending Public ServiceDominant Logic. Public Management Review 18(5): 673-691.

Alonso, José M., Rhys Andrews, Judith Clifton, and Daniel Diaz-Fuentes. 2019. Factors Influencing Citizens' Co-Production Of Environmental Outcomes: A Multi-Level Analysis. Public Management Review 21(11): 1620-1645.

Arnstein, Sherry R. 1969. A Ladder of Citizen Participation. Journal of the American Institute of Planners 35(4): 216-224.

Benjamin, Lehn M., and Jeffrey L. Brudney. 2018. What Do Voluntary Sector Studies Offer Research on Co-Production? Pages 49-60 in Taco Brandsen, Trui Steen, and Bram Verschuere (eds.) Co-Production and Co-Creation: Engaging Citizens in Public Services. New York: Routledge.

Bovaird, Tony. 2007. Beyond Engagement and Participation: User and Community Coproduction of Public Services. Public Administration Review 67(5): 846-860.

Bovaird, Tony, Gregg G. Van Ryzin, Elke Loeffler, and Salvador Parrado. 2015. Activating Citizens to Participate in Collective Co-Production of Public Services. Journal of Social Policy 44(1): 1-23.

Bovaird, Tony, Elke Loeffler, Sophie Yates, Gregg Van Ryzin, and John Alford. 2021. International survey evidence on user and community co-delivery of prevention activities relevant to public services and outcomes. Public Management Review, DOI: $10.1080 / 14719037.2021 .1991665$ 
Brandsen, Taco, and Marlies E. Honingh. 2016. Distinguishing Different Types of Coproduction: A Conceptual Analysis based on the Classical Definitions. Public Administration Review 76(3): 427-435.

Brandsen, Taco, and Victor Pestoff. 2006. Co-production, The Third Sector and the Delivery of Public Services: An Introduction. Public Management Review 8(4): 493-501.

Brandsen, Taco, Trui Steen, and Bram Verschuere (eds.) 2018. Co-Production and Co-Creation: Engaging Citizens in Public Services. New York: Routledge.

Brudney, Jeffrey L., and Robert E. England. 1983. Toward a definition of the coproduction concept. Public Administration Review 43(1): 59-65.

Cheng, Yuan (Daniel). 2019. Exploring the role of nonprofits in public service provision: moving from coproduction to cogovernance. Public Administration Review 79(2): 203214.

Cheng, Yuan (Daniel). 2020. "Bridging the great divide: toward a comparative understanding of coproduction." Journal of Chinese Governance 5(1): 1-7.

Dudau, Adina, Russ Glennon, and Bram Verschuere. 2019. Following the Yellow Brick Road? (Dis)Enchantment with Co-Design, Co-Production and Value Co-Creation in Public Services. Public Management Review 21(11): 1577-1594.

Dzigbede, Komla D., Sarah Beth Gehl, and Katherine Willoughby. 2020. Disaster resiliency of US local governments: Insights to strengthen local response and recovery from the COVID-19 pandemic. Public Administration Review 80(4): 634-643.

Ferris, James M. 1988. The Use of Volunteers in Public Service Production: Some Demand and Supply Considerations. Social Science Quarterly 69(1): 3-23. 
Gazley, Beth, Chantalle LaFontant, and Yuan Daniel Cheng. 2020. Does coproduction of public services support government's social equity goals? The case of US state parks. Public Administration Review 80 (3): 349-359.

Gazley, Beth, Yuan Daniel Cheng, and Chantalle Lafontant. 2018. Charitable Support for U.S. National and State Parks through the Lens of Coproduction and Government Failure Theories." Nonprofit Policy Forum 9(4): 1-16.

International City/County Management Association. 2017 Alternative Service Delivery Survey - Summary of Survey Results. Washington, DC: ICMA (2019). (Accessed July 20, 2020). http://icma.org.

Jakobsen, Morten. 2013. Can government initiatives increase citizen coproduction? Results of a randomized field experiment. Journal of Public Administration Research and Theory 23(1): 27-54.

Jakobsen, Morten, and Simon Calmar Andersen. 2013. Coproduction and equity in public service delivery. Public Administration Review 73(5): 704-713.

Jilke, Sebastian, Bart Meuleman, and Steven Van de Walle. 2015. We Need to Compare, but How? Measurement Equivalence in Comparative Public Administration. Public Administration Review 75(1): 36-48.

Kang, Sinah, and Gregg G. Van Ryzin. 2019. Coproduction and Trust in Government: Evidence from Survey Experiments. Public Management Review 21(11): 1646-1664,

Lamothe, Meeyoung, Scott Lamothe, and Elizabeth Bell. 2018. Understanding Local Service Delivery Arrangements: Are the ICMA ASD Data Reliable? Public Administration Review 78(4): 613-625. 
Letki, Natalia, and Trui Steen. 2021. Social-Psychological Context Moderates Incentives to Coproduce: Evidence from a Large-Scale Survey Experiment on Park Upkeep in an Urban Setting. Public Administration Review 81(5): 935-950.

Loeffler, Elke, and Tony Bovaird. 2016. User and Community Co-Production of Public Services: What Does the Evidence Tell Us? International Journal of Public Administration 39(13): 1006-1019.

Loeffler, Elke, Salvador Parrado, Tony Bovarid, and Gregg Van Ryzin. 2008. "If You Want To Go Fast, Walk Alone. If You Want To Go Far, Walk Together: " Citizens and the CoProduction of Public Services. Paris: Ministry of Public Finance and Public Services.

Marvel, Mary K., and Howard P. Marvel. 2007. Outsourcing oversight: A comparison of monitoring for in-house and contracted services. Public Administration Review 67(3): $521-530$.

McMullin, Caitlin. 2019. Coproduction and the Third Sector in France: Governmental Traditions and the French Conceptualization of Participation. Social Policy and Administration 53(2): 295-310.

Muthén, Bengt. 1978. Contributions to factor analysis of dichotomous variables. Psychometrika 43(4): 551-60.

Muthén, Bengt. 1983. Latent variable structural equation modeling with categorical data. Journal of Econometrics 22(1-2): 43-65.

Nabatchi, Tina, Alessandro Sancino, and Mariafrancesca Sicilia. 2017. Varieties of participation in public services: the who, when, and what of coproduction. Public Administration Review 77(5): 766-776. 
Nalbandian, John. 1999. Facilitating community, enabling democracy: New roles for local government managers. Public Administration Review 59(3): 187-197.

Nederhof, Anton J. 1985. Methods of Coping with Social Desirability Bias: A Review. European Journal of Social Psychology 15(3): 263-280.

Norris, Donald F., Laura Mateczun, Anupam Joshi, and Tim Finin. 2019. Cyberattacks at the Grass Roots: American Local Governments and the Need for High Levels of Cybersecurity. Public Administration Review 79(6): 895-904.

Nowlin, Matthew C. 2011. "Theories of the policy process: State of the research and emerging trends." Policy Studies Journal 39 (s1): 41-60.

Osborne, Stephen P. 2018. From public service-dominant logic to public service logic: are public service organizations capable of co-production and value co-creation?. Public Management Review 20(2): 225-231.

Paarlberg, Laurie E., and Sheldon Gen. 2009. Exploring the determinants of nonprofit coproduction of public service delivery: the case of K-12 public education. American Review of Public Administration 39(4): 391-408.

Palumbo, Rocco, and Mohammad Fakhar Manesh. 2021. Travelling along the public service coproduction road: a bibliometric analysis and interpretive review. Online first at Public Management Review.

Parks, Roger B., Paula C. Baker, Larry Kiser, Ronald Oakerson, Elinor Ostrom, Vincent Ostrom, Stephen L. Percy, Martha B. Vandivort, Gordon P. Whitaker, and Rick Wilson. 1981. Consumers as coproducers of public services: some economic and institutional considerations. Policy Studies Journal 9(7): 1001-11. 
Parrado, Salvardor, Gregg G. Van Ryzin, Tony Bovaird \& Elke Löffler. 2013. Correlates of coproduction: evidence from a five-nation survey of citizens. International Public Management Journal 16(1): 85-112.

Pestoff, Victor. 2019. Co-Production and Public Service Management: Citizenship, Governance and Public Services Management. New York: Routledge.

Pollitt, Christopher, and Peter Hupe. 2011. Talking about Government: The Role of Magic Concepts. Public Management Review 13(5): 641-658.

Riccucci, Norma M., Gregg G. Van Ryzin, and Huafang Li. 2016. Representative bureaucracy and the willingness to coproduce: an experimental study. Public Administration Review 76(1): 121-130.

Sabatier, Paul. 2007. Theories of the Policy Process, 2nd ed., Boulder, CO: Westview Press.

Sicilia, Mariafrancesca, Alessandro Sancino, Tina Nabatchi, and Enrico Guarini (2019) Facilitating co-production in public services: management implications from a systematic literature review. Public Money \& Management 39(4): 233-240.

Thijssen, Peter, and Wouter Van Dooren. 2016. Who you are/where you live: do neighbourhood characteristics explain co-production? International Review of Administrative Sciences 82(1): 88-109.

Thomas, John Clayton. 2013. Citizen, customer, partner: Rethinking the place of the public in public management. Public Administration Review 73 (6): 786-796.

Uzochukwu, Kelechi, and John Clayton Thomas. 2018. Who engages in the coproduction of local public services and why? the case of Atlanta, Georgia. Public Administration Review 78(4): 514-526. 
Voorberg, William H., Victor J.J.M Bekkers, and Lars G. Tummers. 2015. A systematic review of co-creation and co-production: embarking on the social innovation journey. Public Management Review 17(9): 1333-1357.

Warner, Mildred E., Austin M. Aldag, and Yunji Kim. 2020. Pragmatic Municipalism: US Local Government Responses to Fiscal Stress. Public Administration Review 81(3): 389-398.

Watson, Douglas J., and Wendy L. Hassett. 2004. Career Paths of City Managers in America's Largest Council-Manager Cities. Public Administration Review 64(2): 192-199.

Whitaker, Gordon P. 1980. Coproduction: citizen participation in service delivery. Public Administration Review 40(3): 240-46. 
Figure 1. The Latent Trait Model for Measuring Coproduction

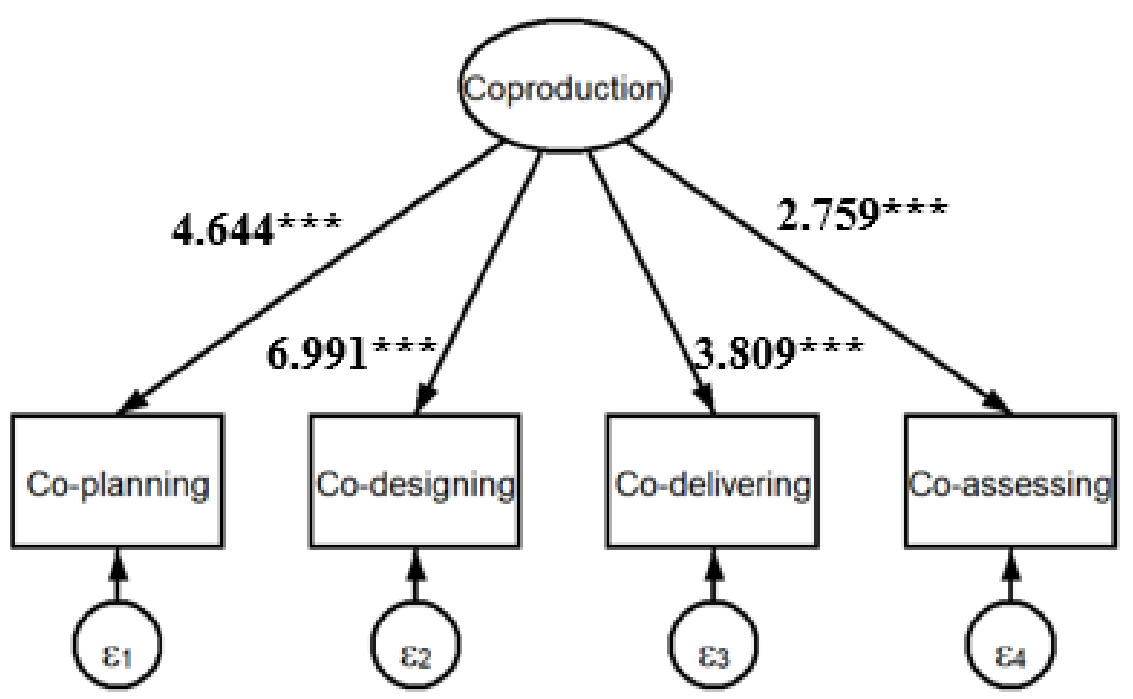

Note: 1) The number on each arrow indicates the unstandardized factor loading of the indicator, which can be interpreted as the unstandardized regression coefficient. The gsem function of Stata/SE 16.0 cannot produce standardized coefficients.

2) The statistical significance of the factor loadings is $* p<.05, * * p<.01, * * * p<.001$.

3) We normalize the latent variable coproduction by constraining its variances to be 1.0. 
Table 1. Frequencies of Coproductive Activities by Local Governments

\begin{tabular}{|c|c|c|c|c|}
\hline Category & Individual Citizens & Group of Citizens & $\begin{array}{c}\text { Citizens as a } \\
\text { whole }\end{array}$ & $\begin{array}{l}\text { Any Citizen } \\
\text { Involvement }\end{array}$ \\
\hline $\begin{array}{l}\text { 1. Co-planning: Does your local } \\
\text { government involve citizens in } \\
\text { planning services (i.e. decisions } \\
\text { on service policies and } \\
\text { funding)? }\end{array}$ & $378(36.91 \%)$ & $539(52.64 \%)$ & $410(40.04 \%)$ & $1024(46.57 \%)^{* * *}$ \\
\hline $\begin{array}{l}\text { 2. Co-designing: Does your local } \\
\text { government involve citizens in } \\
\text { designing services (i.e. decisions } \\
\text { on how services will be arranged } \\
\text { or organized)? }\end{array}$ & $257(38.36 \%)$ & $333(49.70 \%)$ & $242(36.12 \%)$ & $670(30.47 \%)^{* * *}$ \\
\hline $\begin{array}{l}\text { 3. Co-delivering: Does your local } \\
\text { government involve citizens in } \\
\text { delivering services (i.e. using } \\
\text { citizens' labor/expertise to help } \\
\text { deliver services)? }\end{array}$ & $258(42.93 \%)$ & $280(46.59 \%)$ & $204(33.94 \%)$ & $601(27.33 \%)^{* * * *}$ \\
\hline $\begin{array}{l}\text { 4. Co-assessing: Does your local } \\
\text { government involve citizens in } \\
\text { assessing services (i.e. seeking } \\
\text { citizens' online ratings or other } \\
\text { reviews of services)? }\end{array}$ & $309(40.08 \%)$ & $251(32.56 \%)$ & $440(57.07 \%)$ & $771(35.06 \%) * * *$ \\
\hline
\end{tabular}

Note: 1) The first three columns of statistics do not sum to the last column because survey respondents could select multiple responses.

2) The percentages consist of the raw numbers (n's) divided by the number of respondents who reported citizen involvement in any of the categories of co-planning, -designing, -delivering, or -assessing of services. For any citizen involvement the denominator is the total number of respondents reporting that their jurisdiction delivered at least one service. 
3) The t-test results indicate that the differences in means among co-planning, co-designing, co-delivering, and co-assessing are statistically significant at $* * * p<.001$. For the simplicity of interpretation, only a t-test for any citizen involvement category is calculated. 
Table 2. Tetrachoric Correlation Matrix of Coproductive Activities

\begin{tabular}{lllll}
\hline Variables & Co-planning & Co-designing & Co-delivering & Co-assessing \\
\hline Co-planning & 1.0000 & & & \\
Co-designing & 0.8833 & 1.0000 & & \\
Co-delivering & 0.7992 & 0.8524 & 1.00000 & \\
Co-assessing & 0.7498 & 0.7788 & 0.8036 & 1.0000 \\
\hline
\end{tabular}

Note: All tetrachoric correlations are statistically significant at $\mathrm{p}<.001$.

Table 3. Factor Loadings and Unique Variances for Coproductive Activities

\begin{tabular}{lll}
\hline & Factor 1 & Uniqueness \\
\hline Co-planning & 0.9006 & 0.1889 \\
Co-designing & 0.9469 & 0.1033 \\
Co-delivering & 0.9108 & 0.1705 \\
Co-assessing & 0.8453 & 0.2855 \\
\hline
\end{tabular}


Table 4. Factor Loadings for Coproductive Activities by Subgroups

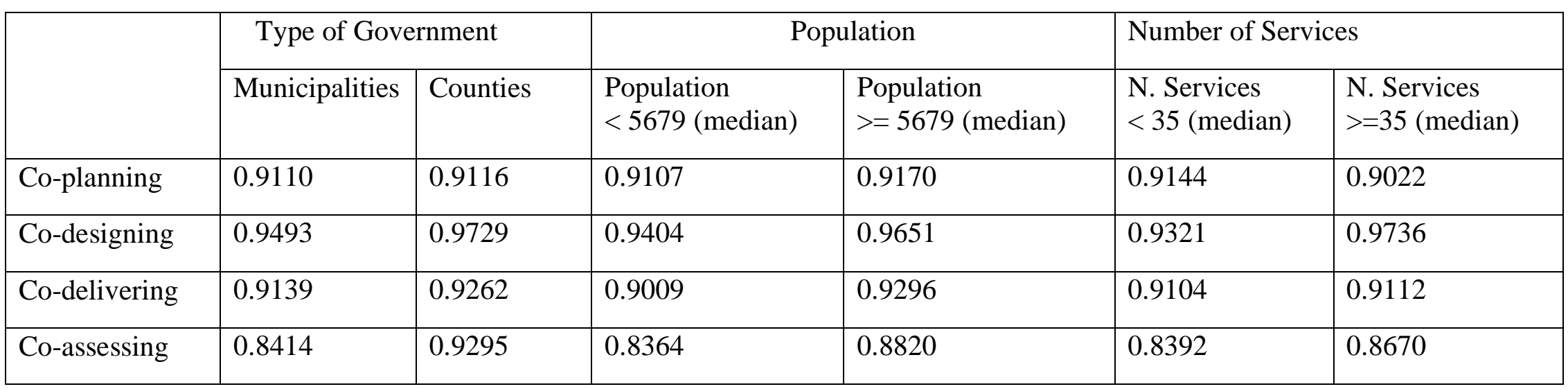

Note: The Eigenvalue of the first factor solution surpasses 2.5 in each subgroup. The Eigenvalue of the second factor is less than 0.5 for each subgroup. 
Table 4. Factor Loading for Coproductive Activities by Subgroups (cont.)

\begin{tabular}{|c|c|c|c|c|c|c|}
\hline & Form of $\mathrm{G}$ & rnment & & & & \\
\hline & $\begin{array}{l}\text { More } \\
\text { Professional }\end{array}$ & $\begin{array}{l}\text { Less } \\
\text { Professional }\end{array}$ & Northeast & Northcentral & South & West \\
\hline Co-planning & 0.9015 & 0.9146 & 0.9115 & 0.9264 & 0.9180 & 0.8420 \\
\hline Co-designing & 0.9509 & 0.9303 & 0.9341 & 0.9677 & 0.9387 & 0.9547 \\
\hline Co-delivering & 0.8951 & 0.9218 & 0.9182 & 0.9459 & 0.9244 & 0.8196 \\
\hline Co-assessing & 0.8157 & 0.8623 & 0.8489 & 0.8987 & 0.8426 & 0.7781 \\
\hline
\end{tabular}

Note: The Eigenvalue of the first factor solution surpasses 2.5 in each subgroup. The Eigenvalue of the second factor is less than 0.5 for each subgroup. 
Table 5. Coproduction Scale and Percentages of Coproductive Activities by Subgroups

\begin{tabular}{|l|l|l|l|l|l|l|}
\hline \multirow{2}{*}{} & \multicolumn{2}{|l|}{ Type of Government } & \multicolumn{2}{|c|}{ Population } & \multicolumn{2}{l|}{ Number of Services } \\
\cline { 2 - 7 } & Municipalities & Counties & $\begin{array}{l}\text { Population } \\
<5679 \text { (median) }\end{array}$ & $\begin{array}{l}\text { Population } \\
>=5679 \text { (median) }\end{array}$ & $\begin{array}{l}\text { N. Services } \\
<35(\text { median) }\end{array}$ & $\begin{array}{l}\text { N. Services } \\
>=35(m e d i a n)\end{array}$ \\
\hline $\begin{array}{l}\text { Coproduction } \\
\text { (latent trait } \\
\text { model) }\end{array}$ & -0.039 & -0.087 & $-0.105^{* *}$ & $0.006^{* *}$ & $-0.237 * * *$ & $0.118 * * *$ \\
\hline Any Stage & $56.37 \% *$ & $49.57 \% *$ & $51.77 \% * *$ & $58.48 \% * *$ & $44.62 \% * * *$ & $64.57 \% * * *$ \\
\hline Co-planning & $47.19 \%$ & $43.23 \%$ & $45.35 \%$ & $47.66 \%$ & $39.04 \% * * *$ & $53.10 \% * * *$ \\
\hline Co-designing & $30.40 \%$ & $30.84 \%$ & $27.61 \% * *$ & $33.04 \% * *$ & $23.19 \% \% * * *$ & $36.79 \% * * *$ \\
\hline Co-delivering & $27.32 \%$ & $27.38 \%$ & $25.50 \% *$ & $28.98 \% *$ & $19.37 \% * * *$ & $34.24 \% * * *$ \\
\hline Co-assessing & $35.48 \%$ & $32.85 \%$ & $29.05 \% * * *$ & $40.48 \% * * *$ & $22.11 \% * * *$ & $46.30 \% * * *$ \\
\hline
\end{tabular}

Note: 1) The t-test results indicate that the differences in means by the corresponding subgroups are statistically significant at $* \mathrm{p}<$ $.05, * * \mathrm{p}<.01, * * * \mathrm{p}<.001$.

2) We normalize the latent variable coproduction by constraining its variance to be 1.0. Therefore, there are negative values of the coproduction scale predicted by the latent trait model. 
Table 5. Coproduction Scale and Percentages of Coproductive Activities by Subgroups (cont.)

\begin{tabular}{|l|l|l|l|l|l|l|}
\hline \multirow{2}{*}{} & \multicolumn{2}{|l|}{ Form of Government } & \multicolumn{3}{c|}{ Region } \\
\cline { 2 - 7 } & $\begin{array}{l}\text { Less } \\
\text { Professional }\end{array}$ & $\begin{array}{l}\text { More } \\
\text { Professional }\end{array}$ & Northeast & Northcentral & South & West \\
\hline $\begin{array}{l}\text { Coproduction } \\
\text { (latent trait } \\
\text { model) }\end{array}$ & $-0.114 * * *$ & $0.048 * * *$ & $-0.095^{* * *}$ & $-0.135 * * *$ & $0.0086^{* * *}$ & $0.160 * * *$ \\
\hline Any Stage & $56.27 \% * * *$ & $61.35 \% * * *$ & $53.32 \% * *$ & $48.57 \% * * *$ & $58.52 \% * * *$ & $70.36 \% * * *$ \\
\hline Co-planning & $49.22 \% *$ & $49.45 \% *$ & $46.46 \% * *$ & $41.92 \% * * *$ & $47.59 \% * * *$ & $57.19 \% * * *$ \\
\hline Co-designing & $30.47 \% * *$ & $34.17 \% * *$ & $29.20 \% * *$ & $27.14 \% * *$ & $33.33 \% * *$ & $36.22 \% * *$ \\
\hline Co-delivering & $27.12 \% * *$ & $30.90 \% * *$ & $25.22 \% *$ & $25.66 \% *$ & $27.41 \% *$ & $34.43 \% *$ \\
\hline Co-assessing & $35.48 \% * * *$ & $42.79 \% * * *$ & $28.32 \% * * *$ & $28.87 \% * * *$ & $42.22 \% * * *$ & $48.80 \% * * *$ \\
\hline
\end{tabular}

Note: 1$)$ The t-test results indicate that the differences in means by the corresponding subgroups are statistically significant at $* \mathrm{p}<$ $.05, * * \mathrm{p}<.01, * * * \mathrm{p}<.001$

2) We normalize the latent variable coproduction by constraining its variances to be 1.0. Therefore, there are negative values of the coproduction scale predicted by the latent trait model. 